\title{
He Trazos de una historia: San José desde la mirada de Juan Bernal Ponce 1976-1990
}

\author{
Traces of a story: San José from the \\ perspective of Juan Bernal Ponce \\ 1976-1990
}

\section{Traços de uma história: San José sob a perspectiva de Juan Bernal Ponce 1976-1990}

Marcela Ramírez-Hernández ${ }^{1}$

\section{Resumen}

A partir de textos inéditos, dibujos y artículos, este texto procura un acercamiento a la faceta del arquitecto chileno Juan Bernal Ponce como historiador de las ciudades y de la arquitectura. Se enfatiza en sus estudios del espacio urbano de San José. Bernal Ponce propuso un análisis detallado de múltiples aspectos del entorno, estudiando diacrónicamente la constitución y la trasmutación espacial de dicha capital, la distribución poblacional, la expansión urbanística y las características de los estilos arquitectónicos, entre otros. En su obra es evidente no solo un aporte significativo al conocimiento de la historia urbana costarricense, sino que también es palpable el proceso de reconocimiento del país receptor experimentado por el autor durante su exilio, materializado en la continuidad y minuciosidad de sus pesquisas sobre el paisaje metropolitano.

Palabras clave: Arquitectura; San José, Costa Rica; exilio; Chile.

\begin{abstract}
Based on unpublished texts, drawings and articles, the present work provides a glimpse into the facet of the Chilean architect Juan Bernal Ponce as a historian of cities and architecture. His studies of San José's (Costa Rica) urban space are emphasized. Bernal Ponce proposed a detailed analysis of multiple aspects of the surroundings, diachronically studying the constitution and

1 Historiadora, Máster Scientae en Historia Aplicada de la Universidad Nacional. Investigadora en el Instituto de Estudios Latinoamericanos, Universidad Nacional, Costa Rica y docente en la Escuela de Historia de esa misma casa de estudios. ORCID: https://orcid.org/0000-0002-4004-4003
\end{abstract}


spatial transmutation of San José, its population distribution, urban expansion and the characteristics of architectural styles, among others. In his work, it is evident not only a significant contribution to the knowledge of Costa Rican urban history, but the process of recognition of the foster country experienced by the author during his exile is also palpable; both attributes materialized in the continuity and thoroughness of his research on the metropolitan landscape.

Keywords: Architecture; San José, Costa Rica; Exile; Chile.

\section{Resumo}

Baseado em textos inéditos, desenhos e artigos, este texto fornece uma aproximação da faceta do arquiteto chileno Juan Bernal Ponce como historiador das cidades e da arquitetura. Ele ressalta em seus estudos sobre o espaço urbano de San José. Bernal Ponce propôs uma análise detalhada de múltiplos aspectos do meio ambiente, estudando diacronicamente a constituição e transmutação espacial da referida capital, a distribuição populacional, a expansão urbana e as características dos estilos arquitetônicos, entre outros. Em seu trabalho, é evidente não apenas uma contribuição significativa ao conhecimento da história urbana da Costa Rica, mas também o processo de reconhecimento do país receptor experimentado pelo autor durante o exílio, materializado na continuidade e profundidade de suas investigações sobre a paisagem metropolitana.

Palavras-chave: Arquitetura; San José, Costa Rica; Exílio; Chile.

La producción del conocimiento en torno a la transformación espacial y al desarrollo urbano en Costa Rica se ha nutrido de diversas disciplinas y se perfila como un campo en expansión, que explica los motivos e implicaciones del acelerado proceso de transformación del paisaje. Esta área temática obtuvo significativos aportes de la mano de varios chilenos exiliados quienes, con sus actitudes disciplinarias, proporcionaron nuevas y ampliadas perspectivas a la investigación de la arquitectura, las ciudades y sus dinámicas sociales ${ }^{2}$. Entre sus exponentes encontramos al arquitecto, pintor, grabador y académico Juan Jesús Bernal Ponce, quien, desde su arribo a Costa Rica en 1974, se involucró - quizá primero por necesidad, luego por pasión - en la investigación y análisis de la historia de la arquitectura costarricense, y de la transmutación de sus espacios urbanos y costeros en el devenir histórico.

Si bien su producción gráfica y escrita recorre geografías variopintas, este texto se enfocará en la faceta del chileno como estudioso de la historia de la arquitectura y el espacio de la ciudad de San José. El estudio de dicha capital forma parte de un conjunto de investigaciones y obras artísticas atinentes a las urbes que elaboró Bernal

2 Entre los chilenos que han estudiado el cambio espacial y la planificación urbana, además de Juan Bernal Ponce, encontramos a Miguel Morales, quien fuera geógrafo con énfasis en planificación urbana. Fue académico de la Escuela de Geografía de la Universidad Nacional de Costa Rica y autor de variedad de artículos y libros sobre la organización espacial costarricense y latinoamericana. 
Ponce desde etapas tempranas de su trayectoria profesional, donde la historia de la arquitectura es una de sus principales inquietudes intelectuales. Su bagaje cultural y de conocimientos especializados se nutrieron, no solo de su preparación universitaria, sino, ante todo, de sus constantes viajes, los que aprovechó para observar y reproducir detenidamente con la pluma y el lápiz, los entornos observados. Sobre su pasión por las ciudades, escribió a modo de remembranza:

Son la obra maestra de las civilizaciones, sus calles, sus monumentos y su paisaje emiten intensos mensajes de historia y belleza. Cada ciudad despliega encanto propio. San Francisco impresiona por su bahía, Venecia por un dédalo de callejuelas con una avenida acuática, Nueva York aturde por su monumentalidad desordenada y en las avenidas de Berlín resuenan los ecos dramáticos de la historia reciente. París fue mi amor de juventud, vuelvo a él en todas las ocasiones. (Bernal Ponce, 2000, p. 9)

La propuesta de este primer esbozo investigativo estaría incompleta si esa fascinación por el espacio y la acción humana no se estudiara desde la experiencia del exilio. El exilio es siempre político y es, además, lejanía y añoranza del territorio natal, que en el caso que nos ocupa, se tornó transnacional pues la avidez del artista por explorar el mundo impulsó la constitución de diálogos con paisajes diversos, a partir de los que creó una red de puntos de referencia espaciales que contribuyeron a articular su experiencia del destierro, así como su proyección como sujeto y artista cosmopolita. Por ende, el análisis propuesto mantiene el suceso del exilio como marco de fondo, con el fin de indagar cómo Juan Bernal procuró apropiarse y reconocer a fondo un paisaje que no le era propio, que no era el de sus recuerdos, pero que fue el que le acogió y del cual, tal vez, procuró aprehenderse como estrategia para enfrentar el desarraigo y plasmar, en su crítica, una posición política y una mirada del mundo.

\section{Una breve reseña sobre un hombre nómada}

Valparaíso, París, San Petersburgo, San Francisco, Quito, La Habana, Antioquía, Argel, Roma, Venecia, San José... son muchas las ciudades y pueblos que a lo largo de su vida visitó Juan Bernal Ponce, un largo camino que inició con sus primeros pasos como estudiante de artes y en la academia. Oriundo de Valparaíso en Chile, por recomendación de un profesor de la secundaria, inició a la edad de 16 años su ruta de aprendizajes en el Taller de Grabado de Carlos Hermosilla en la Escuela de Bellas Artes de Viña del Mar; contó, además, con la guía del pintor alemán Hans Soyka.

Durante esta etapa de juventud desarrolló, también, su fascinación por la lectura prefiriendo la literatura clásica y las biografías de personajes admirados como Ludwing van Beethoven. Al gusto por la música, sumó el descubrimiento del jazz de la mano de amigos con quienes departía en tertulias en las que discutían sobre 
política y leían a Neruda (Bernal, 16 de octubre 1991, p. 3). El entorno viñamarino atizó las inquietudes intelectuales de Ponce, al ser un sitio de confluencia de artistas locales y extranjeros, así como un momento de efervescencia política que definió sus líneas de pensamiento.

A partir de 1957, complementó su preparación con estudios en arquitectura en la Universidad de Chile, donde su interés por el análisis de la constitución de las ciudades quedó manifiesta en la única obra que escribió en su país natal, que fue, además, su tesis de licenciatura, Valparaíso: Arquitectura de una ciudad anfiteatro. En ella se propone un análisis de la constitución de los entornos populares de la región y la imagen de la ciudad, elaborada al lado de Glenda Kapstein en 1965, a partir de la que se derivaría un artículo publicado en el Boletín de la Universidad de Chile (Bernal Ponce, 1967).

En medio de su preparación académica, empezó con lo que sería un amplio historial de viajes alrededor del mundo, cuando al dirigirse hacia París en barco en 1962, conoció al lado de algunos compañeros de carrera, varias ciudades del Viejo Continente. En un texto autobiográfico, describe su encanto por estos paisajes recién descubiertos:

Bajamos ansiosos en cada puerto, nos perdimos en las callejuelas de Lisboa, empedradas de colores; Barcelona se convirtió en un paseo frenético por las torres de Gaudí, la Pedrera y el Barrio Gótico, Desde Génova llegamos a Florencia, Assis y Siena. Casi no podía creer que pisaba las mismas calles de los maestros renacentistas, que tenía ante mí al David de Miguel Ángel o la Primavera de Boticelli. El Ponte Vecchio era igual al óleo que admiraba de niño en el Museo de Valparaíso, el agua del Arno era verde botella, las casas con los mismos tonos ocres y sienas y el aire soplaba congelado por el invierno toscano. (Bernal Ponce, 16 de octubre 1991, p. 7)

Residió durante un año en la capital francesa con una beca en artes plásticas con especialización en grabado, estudiando en la Academie Ranson y en Atelier 17 (Bernal Ponce, s. f. Curriculum Vitae) a cargo de William Stanley Hayter, en cuyo taller el "fuerte era el método de poner color con tintas adelgazadas con aceite, que no se mezclaban entre si”" (Bernal Ponce, 16 de octubre 1991, p. 9). Esta técnica de superposición de colores caracterizaría el resto de su obra en esta rama artística.

Como militante de izquierda, a inicios de los años setenta se involucró en el proyecto allendista, participando en proyectos de carácter popular, como la construcción de tres murales en cerámica en el Hospital del Trabajador en Santiago (Museo de Bellas Artes, s. f.), en calidad de colaborador en la Exposición Internacional de la Vivienda y dibujando afiches pedagógicos para distribuir en los barrios obreros santiagueños 
con el fin de promover la participación ciudadana. Integró iniciativas colectivas al lado de artistas chilenos e internacionales montando exposiciones para denunciar el intervencionismo extranjero y las estrategias de boicot contra el gobierno de Allende, además de donar obras al Museo de la Solidaridad ${ }^{3}$ (Bernal Ponce, 16 de octubre 1991, p.16).

Al momento del golpe de Estado, tenía diez años de trabajar en la Universidad de Chile, específicamente en la Facultad de Arquitectura y en la carrera de Paisajismo (Bernal Ponce, Curriculum Vitae). Además, había consolidado su carrera como arquitecto con diversos proyectos, como la construcción del edificio sede de la Conferencia de las Naciones Unidas en Comercio y Desarrollo (UNCTAD, por sus siglas en inglés), para el que diseñó el techo vitral en acrílico del salón de entrada. El proyecto finalizó en 1972 y hoy día es el Centro Cultural Gabriela Mistral.

Como efecto de la dictadura, Ponce fue destituido de su puesto universitario y experimentó la incertidumbre de la persecución por su asociación con partidos políticos proscritos:

Las atrocidades de la represión llegaban filtradas por una cortina de pánico, el ejército allanó todos los talleres del barrio de Villavicencio, encontré todas mis cosas patas arriba y el agua corriendo. Luego llegaron una tarde, cerrando todo el pasaje por ambos lados, me interrogaron sobre armas, literatura subversiva y si trabajaba en teatro, fueron relativamente decentes, no me llevaron. (Bernal Ponce, 16 de octubre 1991, p. 17)

Valiéndose de una amplia red social de artistas y arquitectos, muchos de ellos ya en el exilio, decidió trasladarse hacia Costa Rica luego de una breve estancia en Cali, Colombia, a donde viajó con el doble propósito de salir de Chile y recibir el Premio de Honor en la Bienal de Artes Gráficas. Arribó a tierras centroamericanas el 4 febrero de 1974 para atender la posibilidad de un contrato laboral en la recién fundada Escuela de Arquitectura (1972) de la Universidad de Costa Rica, acuerdo logrado por la mediación de un colega chileno, Fernán Meza Wever (Goering, comunicación personal, 28 de setiembre 2018) quien lo contactó con los creadores de la unidad académica.

Se insertó en el proceso de configuración de la Escuela impartiendo varios cursos, así como talleres de grabado que dirigió a partir de 1979 con el proyecto Arquigraba. Entre los aportes a la Escuela de Arquitectura, estuvo el desarrollo de Ciudades e

3 El Museo de la Solidaridad Salvador Allende, fue creado en 1971 con el objetivo de ser un espacio artístico dirigido a apoyar al pueblo de Chile, albergó obras de autores nacionales e internacionales identificados con el proyecto político del gobierno de la Unidad Popular (Museo de la Solidaridad, s.f.) 
Historia, materia en la que Ponce aprovechó el bagaje adquirido desde antes del exilio para su quehacer docente, a la vez que dicha asignación lo impulsó a ampliar su repertorio de publicaciones con escritos sobre el espacio urbano y ciertos estilos arquitectónicos, temas que desarrolló a cabalidad durante los años que vivió en este país.

Sin embargo, esta primera fase de su residencia fue de adaptación. Su expareja rememora que para el pintor los primeros años de permanencia en Costa Rica fueron bastante difíciles, pues se mostraba insatisfecho con las pocas alternativas que le ofrecía el país en ese momento: consideraba que el ambiente era pueblerino y la universidad, un recinto aún en formación con poco que ofrecer (Goering, comunicación personal). No es de extrañar su posible desánimo, si se toma en cuenta que Bernal Ponce conoció a cabalidad y era miembro del dinámico mundo artístico chileno de las décadas de 1960 y 1970, y recorrió los sitios más bohemios de París, donde conoció a importantes artistas de vanguardia. En otras palabras, tenía acceso a espacios de sociabilidad que lo conectaron con tendencias artísticas y en los que era un sujeto reconocido, de los que obtuvo aprendizajes y validación en un pujante marco cultural; no obstante, repentinamente, se alejó de estos sitios de referencia a causa de la crisis política. A pesar de los efectos que produjo esta ruptura, es necesario indicar los potenciales beneficios en la constitución del pensamiento intelectual: “... esta constelación de exclusión cultural que sufre el exiliado, junto con su insistencia a rechazar y de superar permanentemente dicha exclusión reclamando su pertenencia a esta cultura y/o nación, será significativa para su producción intelectual y cultural" (Nitschack, 2010, p. 233).

Ante la premura de su salida de Chile, arribó sin apoyo económico ni materiales de trabajo, de manera que le tomó varios años establecer un taller adecuado para sus labores de grabado. Aún a tres años de su llegada, con la esperanza de hallar nuevos panoramas de residencia, intentó gestionar oportunidades de contratación en México y España (Goering, comunicación personal), buscando quizás, un medio artístico amplio y que le fuera familiar, para aspirar a una mayor proyección local e internacional.

Lo anterior, aunado a la cita de Horst Nictschack permite conjeturar, entonces, que en las primeras fases de su experiencia exiliar, Bernal Ponce quiso irse de Costa Rica por el deseo de encontrar un ambiente estimulante que sustituyera al antes conocido. Reclamaba un sitio al cual pertenecer y ser, con posibilidades semejantes a las que gozó otrora en Chile, pues colaboró directamente para el proyecto allendista y trabajó codo a codo con renombrados arquitectos y pintores. ¿Acaso buscaba un hogar sustituto, un sitio que le ayudara a llenar los vacíos producidos por el abandono forzado de sus sitios primordiales de sociabilidad? 
Pese al distanciamiento obligado, otro aspecto que se debe contemplar es que en Costa Rica el artista fue miembro de una red social de artistas y profesionales de diversas disciplinas, tanto suramericanos como centroamericanos, así logró, paulatinamente, articular nuevas sociabilidades útiles para la discusión, el diálogo y el esparcimiento. Una de sus amistades fue el pintor Julio Escámez Carrasco a quien conoció en su nativo Chile y con quien compartía, entre otras cosas, la admiración por el poeta Pablo Neruda de quien Escámez era allegado (Oliva, 2019, en prensa). Contrario a Escámez, quien mantuvo un perfil relativamente bajo en términos de exposición pública y quien pocas veces pintó el paisaje del país de acogida, Bernal Ponce organizó exposiciones continuamente para promocionar su trabajo en el que reprodujo desde su particular apreciación, las diversidades paisajísticas del entorno local: desde el trópico caribeño hasta los barrios populares capitalinos.

Sus libretas de apuntes, algunos bocetos y sus grabados representan el paisaje urbano y tropical, lo cual da constancia del inicio de un proceso de aprehensión del sitio receptor. Continuó con su trayectoria artística, tanto en grabado como en pintura; ejerció como académico por 31 años durante los que, aparte de ser docente, se dedicó a la investigación en el campo de la historia de la arquitectura, impulsó talleres y concursos de grabado, publicó varios libros y artículos de revista, ilustró obras literarias y difusivas, a la vez que aprovechó los medios de comunicación universitarios para incursionar con programas sobre urbanismo en Radio Universidad de Costa Rica (Hernández Villalobos, 2018, p.182) y en televisión con el corto "El espacio en que vivimos"; el primero se emitió a mediados de la década de 1980 y el segundo en los años noventa. Fue colaborador permanente de Habitar y escritor asiduo en la Revista del Colegio Federado de Ingenieros y Arquitectos (RCFIA), además de crítico de arte con una columna propia en el periódico La Nación a partir de setiembre de 1994 (Dobles, 10 de setiembre 1994, p. 15B) hasta mediados del año 2000. 


\section{Figura 1. Acuarela de San José}

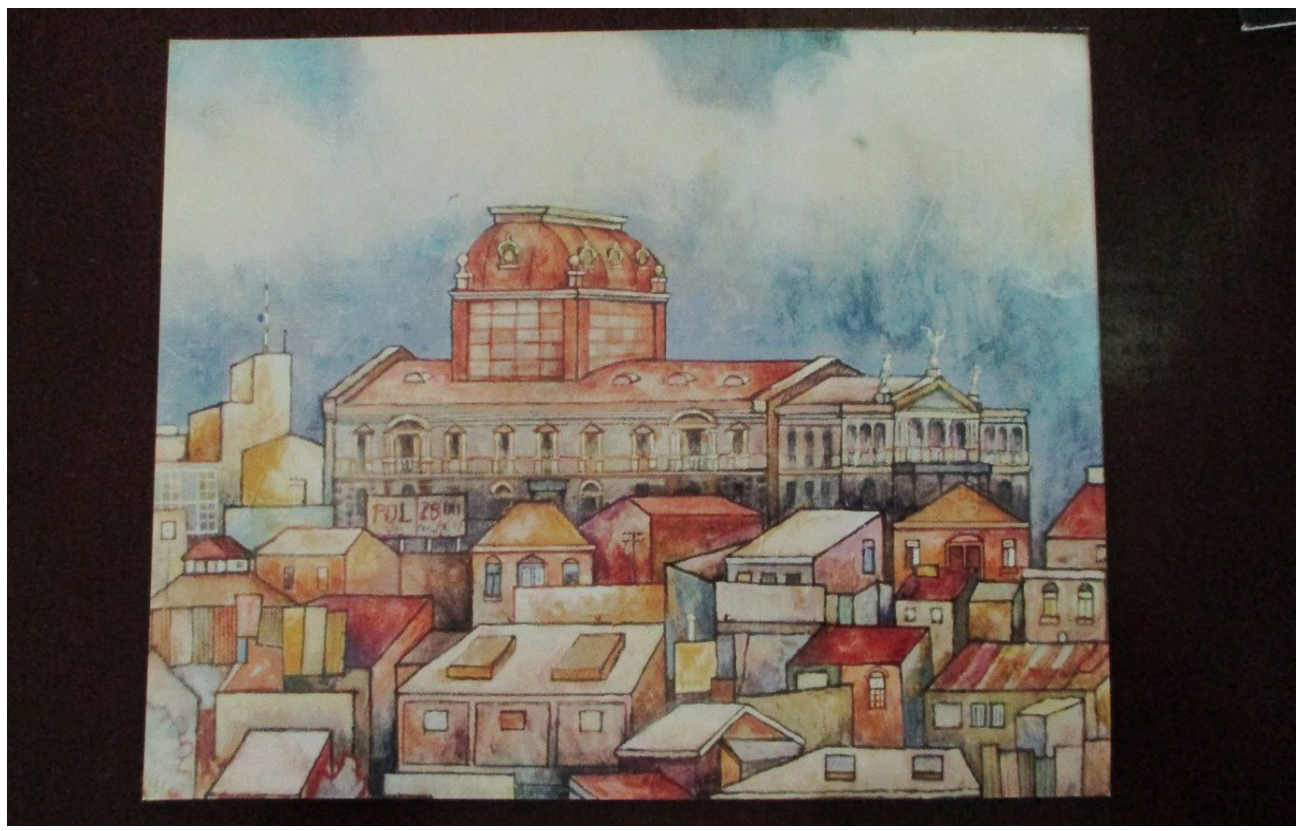

Notas: Colección de obras Bernal Ponce, de Bárbara Goering. Sin fecha.

Bernal Ponce enfatiza el Teatro Nacional, edificio frecuente en su obra pictórica. Además del Teatro por sí mismo, representó en este cuadro una forma y un orden de otras estructuras adyacentes en la que la topografía que plasma no se corresponde con la original, sino que responde a la apreciación e intereses del autor para sobredimensionar ciertas características estructurales y posiblemente, el valor simbólico de la construcción que ocupa la centralidad en la imagen.

Su faceta como artista fue prolífica: expuso en montajes colectivos e individuales en 19 países diferentes y sus obras forman parte de las muestras de múltiples instituciones como la Biblioteca Nacional de París, el Museo Leonardo Da Vinci en Italia, el Museo de Arte Latinoamericano Contemporáneo de Nueva York, el Museo de Arte Costarricense, el Museo Nacional de Bellas Artes de Chile, entre otros (Bernal Ponce, Curriculum Vitae, s. f). Además, varias de sus dibujos forman parte de obras literarias, y componen un corpus cuya propuesta gráfica tiene características de intertexto antes que únicamente ilustrativas (por ejemplo, las imágenes en Cuentos del San José oculto, publicado en 2002).

\section{Analizar y comprender: La escritura como medio para transitar el exilio}

Como se indicó anteriormente, la inquietud de Bernal Ponce por las ciudades nació desde etapas tempranas de su carrera profesional; la nutrió con la observación, la 
sensibilidad social y el estudio meticuloso no solo de la edilicia en su dimensión física y estilística, sino también por medio de investigaciones diacrónicas relativas a la constitución espacial, en las que las variaciones arquitectónicas son discutidas en función de diversas variables del devenir social. Con ello, mantuvo la perspectiva analítica de Hipodamo de Mileto, quien planteó que "la forma de la ciudad era la forma de su orden social” (Rama, 1998, p. 18): identificar los patrones de una ciudad era una forma de conocer y explicar algunas de las peculiaridades de la sociedad que la erigió.

Bien sabido es que dicho interés era uno más entre otros temas recurrentes en su obra gráfica; empero, las ciudades ocuparon la centralidad de sus escritos. Preciso en su apreciación, Efraín Hernández (2018) describe este tipo de representaciones en los grabados:

Bernal penetra en los meandros del concepto de urbe y, con maestría, selecciona edificios paradigmáticos rodeados de detalles y estructuras edilicias (...) la noción de ciudad en Bernal está acompañada de lo humano. En pocas ocasiones el interés se desarrolla exclusivamente en transmitir la sensación que la presencia del edificio produce en el grabador, y aún en muchos casos se percibe la intención de lograr ambientaciones y atmósferas que el entorno citadino consigue por la configuración espacial peculiar que muestra (...) realmente proyecta, porque la comprende, la esencia del paisaje construido por el ser humano; paisaje que viven y experimentan los habitantes de la ciudad. (p. 180)

La arquitectura fue también un medio para ver la poesía y las historias que narran las construcciones, desde una casa hasta el total de los elementos constitutivos de las urbes. En el marco de la primera exposición de Arquigraba de la UCR en 1979, alude brevemente a las potenciales lecturas poéticas que produce la arquitectura:

Los arquitectos ven el mundo circundante mensurable y construible: el artista se regocija en la poesía estable. Pensamos que hacer de esas dos actitudes (las artes plásticas y la arquitectura) una simbiosis creativa aportará sustancialmente al enriquecimiento de nuestra tradición temática, instaladas en la visión bucólica que nuestros maestros ya agotaron en su obra, y que el desarrollo contemporáneo dejó en el pretérito inmediato. (Bernal, 1979)

Las asociaciones que produjo entre su disciplina y otras artes unieron facetas de su vida profesional y de su historia personal, que como se señaló en páginas anteriores, incluyó la avidez por la literatura y la sabida admiración a Neruda no solo como escritor, sino también como arquitecto. De esta manera, en ocasiones propuso 
lecturas de edificaciones desde la mirada poética, plasmadas en su apreciación de la casa del poeta antes mencionado:

Arquitectos formalistas aseguran que las casas de Neruda son banales y no cumplen las reglas del arte; las encuentran disparejas, pueriles y retozonas. Justo en eso está su mérito, su geometría es la del verso libre. Arquitectura en libertad de cátedras, a salvo de las estocadas del criticón académico. (Bernal Ponce, 1988, p. 7)

Utilizando el extracto anterior como ejemplo, son, entonces, las edificaciones puentes para leer a los sujetos y a las sociedades, un tejido que puede ser descrito desde un relato casi literario; esto último, es palpable en el estilo escriturario del pintor.

En lo concerniente a sus inclinaciones temáticas, en una reseña que acompaña una exposición del año 2000 en el Museo de Arte Costarricense, Bernal Ponce presentó una interpretación propia sobre el transcurrir de su obra plástica, por medio de una "cronología" temática y estilística desde sus primeras etapas en Costa Rica, hasta la fecha del evento en cuestión ${ }^{4}$. En esta propuesta explicó brevemente los motivos que guiaron la elaboración de su propuesta gráfica en la que ocupó un sitio significativo el paisaje costarricense: la región Caribe, su pueblo de residencia, Escazú y la ciudad de San José.

En sus escritos especializados, el arquitecto dedicó varias páginas, así como muchos trazos a esta provincia, pues sus estudios sobre la configuración espacial fueron publicados desde momentos tempranos de su residencia en Costa Rica. El acercamiento con el paisaje central josefino ocurrió no solo por ser el sitio de residencia de Bernal Ponce durante sus primeros años de exilio, sino porque en su calidad de arquitecto participó en la formulación de proyectos dirigidos a dinamizar el carácter del entramado urbano en un momento coyuntural de expansión institucional e industrial, como lo fue la década de 1970.

Un ejemplo de la incursión en la planificación en el área citadina fue la propuesta dirigida a la Oficina de Planificación Nacional y Política Económica (OFIPLAN) en la que se planteó la creación de un jardín botánico en las inmediaciones de Calle Blancos en colindancia con el río Torres. Plantea en la justificación, la necesidad de proporcionar un espacio vegetal para el esparcimiento "cuando las actividades propias del núcleo urbano se extienden en el espacio, ocupando antiguas construcciones, cambiando su tipo de uso y también originando nuevas edificaciones" (Bernal y Jankilevich, diciembre 1977, p. 8). Aunque dicha formulación nunca se concretó, requirió el análisis de las variaciones espaciales relacionadas con las áreas

4 Esas etapas y temáticas Bernal Ponce las sistematizó en: 1. El exilio; 2. El trópico; 3. Limón; 4. La música; 5. Las ciudades; 6. Las frutas; 7. El mar; 8. San José y 9. Escazú (2000 a, pp. 8-9). 
de contención urbana y la dinámica de movilización poblacional dentro del anillo capitalino en crecimiento. Lo anterior nos permite suponer que la temprana incursión de Bernal Ponce en este tipo de planes conformó los primeros acercamientos dirigidos al reconocimiento de las especificidades organizativas del territorio capitalino.

Lo señalado previamente nos conduce a dimensionar dos aspectos importantes asociados con el recorrido profesional del chileno y su proyección en el área de la escritura especializada en arquitectura, faceta poco analizada de su quehacer: en primer lugar, antes de arribar a Costa Rica, Bernal Ponce era reconocido por su trabajo pictórico y en grabado, de manera tal que se posicionó en la escena cultural chilena con resultados positivos ${ }^{5}$; en lo concerniente a la arquitectura, su labor se concentró en proyectos de infraestructura, antes que en la escritura (Bernal, 1974, Curriculum Vitae). Segundo, e intrínsecamente vinculado con lo anterior, en el proceso de recabar sus textos (Ramírez, 2018), se ha comprobado que durante su exilio en Costa Rica potenció y amplió su espectro escriturario principalmente en tópicos concernientes a las ciudades latinoamericanas. Entre la amplia variedad de ciudades a las que dedicó líneas, especial interés tuvieron para él Valparaíso -paisaje anclado como primer referente del terruño- y San José -sitio del destierro-, cuyas particularidades procuró descifrar y comprender por medio de la recurrente faena de dibujarla y estudiarla.

Por consiguiente, un repaso por estos textos podría contribuir a trazar una serie de hipótesis concernientes al proceso que atravesó Ponce para adaptarse, aceptar y apropiarse del espacio receptor y, de paso, conocer mejor a la sociedad costarricense. Para él, esto implicó identificar algunos vacíos temáticos y perspectivas de abordaje producidas en Costa Rica en la disciplina de la historia de la arquitectura y, a partir de ello, medir las potencialidades de desarrollar tópicos desde aproximaciones como la comparación y así, generar herramientas para insertarse activamente en la dinámica artística y gremial local.

Al mismo tiempo que se dedicó a la escritura e investigación, continuó en el descubrimiento de nuevos paisajes, los cuales fueron fundamentales en la creación de su narrativa visual y textual de las grandes urbes, mientras adquiría perspectivas y experiencias que fueron la base para su quehacer en las aulas universitarias también. Este ejercicio intelectual de recorrer el mundo y analizar metrópolis y poblados quedó materializado en la totalidad de su herencia escrita y gráfica.

En resumen, con base en Said (1996), es válido afirmar que Bernal Ponce durante su exilio estableció conexiones entre el bagaje adquirido en Chile, con la propuesta

5 Por ejemplo, obtuvo catorce premios entre 1955 y 1973, desde el nivel de estudiante hasta la Mención en Grabado de Casa de las Américas de Cuba en 1969. 
intelectual desarrollada en Costa Rica. Esta última se basó en la realización de un ejercicio que comparaba los diversos panoramas experimentados:

Debido a que el exiliado ve las cosas de lo que ha dejado atrás y, a la vez, en función de los que le rodea aquí y ahora, hay una doble perspectiva que nunca muestra las cosas aisladas. Cada escena o situación en el país de acogida evoca necesariamente su contrapartida con el país de procedencia. Intelectualmente esto significa que una idea o experiencia se ve siempre contrapuesta con la otra, haciéndolas aparecer por lo mismo a ambas en ocasiones bajo una luz nueva e impredecible: de esta yuxtaposición obtiene una mejor y tal vez más universal idea de cómo pensar. (p. 70)

\section{Una entre otras ciudades: Representaciones y relatos sobre San José}

Desde sus primeras publicaciones en las revistas del Colegio Federado de Ingenieros y Arquitectos entre mediados de la década de 1970 hasta sus últimos escritos en los años 2000, el abordaje de Juan Bernal Ponce sobre la arquitectura discurrió entre aspectos diversos, pero manteniendo como común denominador el enfoque histórico y como principal geografía por historiar, el continente americano. Si bien en sus primeros textos en Habitar se focalizó en el Centro Pompidou de París (Bernal Ponce, 1977) y las propiedades de las estructuras metálicas, los escritos con mayor riqueza gráfica, analítica y en contenidos son aquellos relativos a la diversidad de los paisajes caribeños, latinoamericanos y, en menor medida, norteamericanos. Esta paleta temática, si bien mantuvo sus cercanías con las representaciones de su obra gráfica, en su faceta pictórica fue recurrente la presencia de las ciudades europeas.

En contraposición con las imágenes citadinas pintadas por el arquitecto, que reflejan las dimensiones estructurales y organizativas de las ciudades (Hernández, 2018, p.180 ), sus escritos involucran aspectos de índole social en procura de aproximaciones integrales, con la introducción de ejes temáticos transversales concernientes a las políticas económicas, el contexto cultural e, inclusive, anécdotas sobre personajes que recorrieron o describieron los panoramas estudiados ${ }^{6}$, lo cual fortaleció el enfoque histórico de los textos.

Sobre esta misma línea, cabe destacar la presencia en varias de sus publicaciones del periodo colonial como punto de partida para el análisis, con el fin de explicar la indeleble injerencia de la lógica administrativa europea del espacio de la América Colonial, cuyos principales núcleos poblacionales e institucionales fungieron como gestores de los posteriores patrones de expansión urbana e industrial en las capitales del continente. Dicho enfoque no quedó supeditado al estudio de los territorios de

6 En Una biografía de San José es más notable esta propuesta de abordaje, pues introduce anécdotas y relatos sobre la vida de personajes como Lesmes Jiménez, Aquileo Echeverría o Minor Keith. 
dominio español, sino que incluso formuló propuestas comparativas de las ciudades del Caribe -entonces pertenecientes a las coronas francesa e inglesa-, con el objetivo de demarcar las semejanzas y diferencias según colonizadores y ubicación geográfica (Bernal Ponce, 1990b, pp. 22-6; Bernal Ponce, 1993).

A grandes rasgos, su trayectoria investigativa y de producción intelectual se caracterizó por presentar un corrido por diversas rutas, calles e historias, donde figuran, como objetos de estudio, ciudades como Valparaíso (Bernal Ponce, 2000b), La Habana, Ciudad de Panamá y San José (Bernal, 1985; Bernal, 1989).

Para el caso específico de la capital costarricense, Bernal Ponce emitió artículos en revistas desde 1978: le concedió un acápite en "Ocho ciudades y un poeta" (1988), elaboró un borrador biográfico, le dedicó varias páginas en el libro Ciudades del Caribe y Centroamérica (1993a), así como una cantidad significativa de bocetos, pinturas y grabados. En la mayoría de sus textos, la descripción prioriza los aspectos sociohistóricos de la transformación del paisaje y expansión territorial, antes que desde una mirada tecnicista arquitectónica o de planificación, la cual sí empleó en los primeros textos relativos a San José. Definidos por un carácter explicativo, discute, a partir de comparaciones, el origen colonial y los patrones morfológicos de otras ciudades latinoamericanas, con el fin de evidenciar las particularidades configurativas de la "segunda capital de Costa Rica".

"San José y la ciudad americana" (Bernal Ponce, octubre 1978; Bernal Ponce, enero 1979) son dos artículos en los que se identifica un aporte significativo en la propuesta analítica, pues el autor imbrica su capital cultural e intelectual, como punto de partida para producir y sistematizar sus primeras observaciones en relación con un paisaje que apenas estaba conociendo. Con un estilo narrativo que mezcla la descripción literaria con los tecnicismos del urbanismo, uno de las ideas centrales se aboca a establecer las diferencias entre el patrón organizativo colonial de las ciudades anglosajonas frente a las españolas. Pero, principalmente, procura explicar a partir de esa morfología por qué la capital costarricense es diferente a las demás: contrario a los poblados fundados por los hispanos -Santiago, Lima o Bogotá- cuyo crecimiento ocurrió desde un sistema de anillos o "tronco de árbol" que partían de un centro único. San José se constituyó como capital tardía y como ciudad durante la época republicana, por lo que heredó asentamientos poblacionales coloniales que siguieron un modelo de dispersión ${ }^{7}$. Este sistema de pequeños núcleos interconectados tuvo efectos en el aprovechamiento efectivo del suelo e impactó en las

7 En el artículo explica: "si consideramos la región metropolitana como un sistema integrado funcionalmente, y lo es de hecho, nos da una ciudad de bajísima densidad, casi vacía, una ciudad campo, este extraño fenómeno no es posible en el esquema monocéntrico de Bogotá, o Lima, o Santiago" (Bernal Ponce, octubre 1978, p. 28). 
oscilaciones expansivas de la población y las diversas ramas productivas durante el siglo XX. A la vez, la escasa importancia económica de la entonces provincia de Costa Rica y la ausencia de grandes edificaciones y ciudades coloniales impactaron en la configuración espacial al largo plazo.

Como tarea pendiente queda identificar, si en momentos previos, otros autores habían explicado este patrón de crecimiento y constitución irregular. No obstante, lo que es válido afirmar es que estos textos, al proponer un enfoque comparativo, no solo entre países sino en términos temporales -pues hace una lectura diacrónica de la colonia a 1978-, brindan una propuesta metodológica para el estudio del urbanismo con matices históricos, y les dan fuerza y solidez a las argumentaciones. Así mismo, al explicar San José desde el patrón de pequeños pueblos-ciudad conurbados a razón de la expansión residencial y comercial en la última fase del siglo XX, el arquitecto hizo notar las dificultades propias de este sistema urbanístico. En pocas palabras, planteó que dicha distribución creó una ciudad con poca gente y dificultades de viabilidad, cuyas causas se remontan al pasado colonial y a las que había que sumar la ausencia, desde el periodo post independencia, de un plan urbanístico proyectado al largo plazo (Bernal Ponce, enero 1979).

En este punto se acota que la mirada particular con la que Bernal Ponce empezó a evaluar a San José era producto de un tejido de contraposiciones entre su pasado en Chile, su amplio bagaje cultural y su experiencia del exilio. Esta conjugación de experiencias y recursos intelectuales contribuyeron a la creación de propuestas analíticas que constantemente contrastaba un paisaje con otro, aspecto que es palpable no solo en los artículos acá discutidos, sino en la totalidad de su obra textual.

Otro factor para tomar en cuenta es que estos primeros escritos se acompañaron con dibujos en los que Bernal Ponce recreó la pequeña ecúmene josefina de la época republicana (Figuras 2 y 3 ) según la imaginó, a la vez que plasmó el paisaje contemporáneo para contrastar y constatar en ellas los cambios ocurridos. En estas imágenes superpuso las estructuras que él conoció, a la vez que supuso el paisaje del pasado según la descripción de los textos de referencia. La representación del entorno josefino tuvo como requisito previo la observación cuidadosa, el estudio de su historia social y de estilística arquitectónica, para dibujar los pormenores de un entorno que no le era propio. 
Figura 2. El centro de San José en 1900, visto desde la avenida segunda

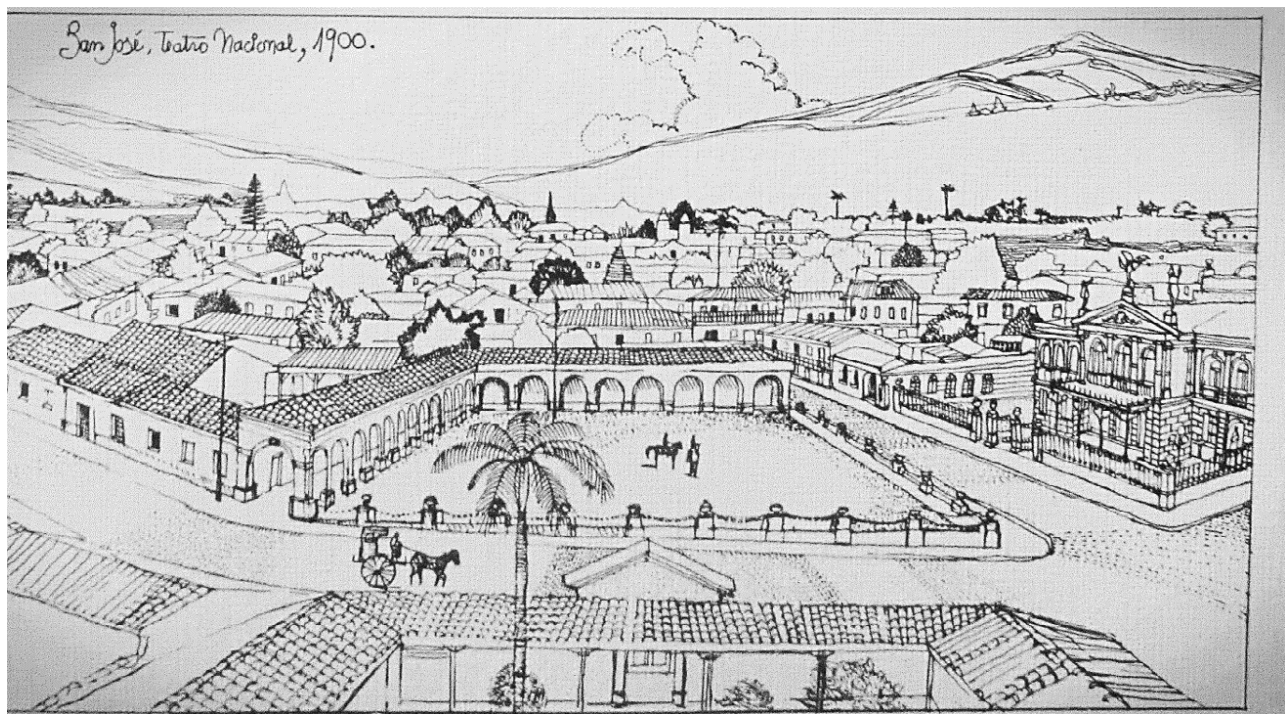

Nota: Juan Bernal Ponce (enero 1979). San José y la ciudad americana. Segunda parte, p. 26.

Figura 3. El centro de San José en 1979, visto desde la avenida segunda

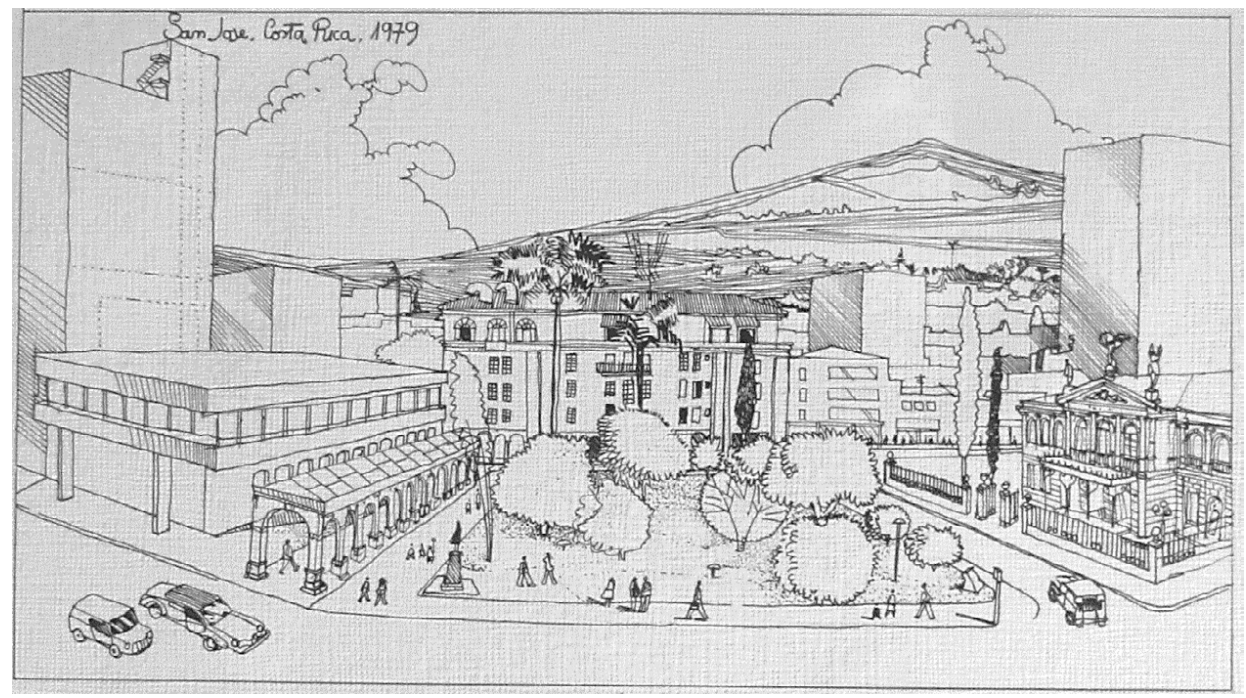

Nota: Juan Bernal Ponce (enero 1979). San José y la ciudad americana. Segunda parte, p. 27 
De esta manera, la escritura y la representación gráfica fueron momentos simultáneos en la construcción de su conocimiento y en el proceso de apropiación espacial, pues, al dibujar la ciudad, la tarea de la observación le permitió descubrir detalles característicos a los cuales buscaría una explicación. Este ejercicio no se redujo a la edilicia, sino que lo trasladó a lo concerniente a los patrones de la distribución espacial ${ }^{8}$. Pero para el caso de Costa Rica, las imágenes y dibujos pueden ser leídos como evidencias de una transición hacia el reconocimiento de la sociedad receptora, valiéndose de las herramientas del arte y la arquitectura, es decir, proponiendo lecturas múltiples del entorno a partir de su capital intelectual y, a la vez, ampliando su bagaje sobre la configuración de lo local.

Con la prolongación de la estancia en el país y el avance en el estudio del panorama capitalino, el contenido de los artículos que publicó, da cuenta de que el paisaje que descubrió no fue solo el del casco metropolitano, sino el de una región central que absorbía poblacionales aledañas a través de rutas extrañamente intervenidas por cafetales y potreros, otorgándole al San José de finales de la década de 1970, lo que él denominó, una fisonomía de "ciudad campo" (Bernal Ponce, enero 1978, p. 28). Deteniéndose en dicha conclusión, tal dictamen coincide con las apreciaciones que Goering narró, él poseía sobre el ambiente pueblerino del país: estas no eran únicamente un juicio de valor producto del exilio, sino que eran también una crítica fundamentada en sus indagaciones y en sus posibilidades para argumentar a partir de comparaciones entre localidades tales como Santiago o Bogotá.

Por otra parte, en su quehacer multifacético, Bernal Ponce tuvo a cargo un programa radial a mediados de los años ochenta. El producto de este trabajo quedó materializado en el primer número de la revista Herencia, del Programa de Rescate y Revitalización del Patrimonio Cultural de la Vicerrectoría de Investigación:

Las ondas de la emisora de la Universidad de Costa Rica emiten cada miércoles mis charlas sobre urbanismo y ciudades; la fortuna ha querido que ese programa radial tenga gran acogida y recibido estímulos internacionales. La Dra. Nora Garita, directora de la radioemisora, me invitó gentilmente a escoger algunos programas y darles forma de libro. (Bernal Ponce, 1988, presentación)

Dicha edición fue redactada en su totalidad por el arquitecto y contenía una nota dedicada a La Sebastiana, la casa de Pablo Neruda, así como otros siete relatos atinentes a poblados tales como Ciudad de México, Panamá, Antigua Guatemala, Granada, Tegucigalpa, Puerto Limón y San José. El común denominador en la

8 La mejor muestra de este tipo de análisis está presente en el capítulo seis del texto Una biografía de San José (1992), basado en los resultados de los Seminarios de Graduación de Historia de las Ciudades de estudiantes de la Escuela de Arquitectura de la UCR, así como en investigaciones e ilustraciones de Bernal Ponce. 
revista es el tipo de descripción del paisaje, pues articula dos dimensiones paralelas: la historia de la configuración espacial y la descripción textual y gráfica de los usos que los sujetos hacían de los espacios públicos o vernáculos.

En el caso josefino, el escrito expone el primer acercamiento del chileno a explicar los orígenes coloniales de la ecúmene de la mano con factores administrativos, económicos y poblacionales. Siguiendo un patrón descriptivo propio de autores como Ricardo Jiménez y Cleto González Víquez -a quienes consultó (Bernal Ponce, 1992, pp. 6-21)-, historizó la variabilidad del espacio en función del levantamiento de edificios que contribuyeron a definir una fisonomía proto citadina y el trazado de las calles (Bernal Ponce, 1988, pp. 20-3). Al respecto, se aclara que la mención de este escrito se hace en el contexto del recorrido de la trayectoria del chileno, pues en momentos previos ya habían sido publicadas por otros autores investigaciones sobre el San José colonial'.

En las publicaciones emitidas entre finales de los ochenta e inicios de 1990, el relato que hasta entonces produjo Bernal Ponce fue completado al aproximarse a diversas variables y etapas históricas, lo cual hizo que sus escritos se proyectaran en ese momento como investigaciones pioneras en el área de la historia de la arquitectura y el urbanismo de San José. En ellos abordó un amplio lapso temporal en el que procuró explicar la transformación espacial no solo del casco central, sino también del proceso distributivo espacial de las áreas aledañas; a la vez que elaboró reseñas sobre importantes arquitectos como Lesmes Jiménez y Jaime Carranza, cuyas obras influyeron en la planificación estilística y urbanística durante la primera fase del Estado Liberal entre 1870 y 1914 (Bernal Ponce, 1992, pp. 43-61; Bernal Ponce, 1989).

Si tomamos en cuenta que cuando el chileno llegó a Costa Rica, San José se encontraba en plena expansión, identificó en un primer momento las marcas distintivas de esta capital en relación con otras y durante su estancia se dedicó a dar seguimiento a las pautas de ordenamiento y segregación poblacional, distribución de las zonas productivas y establecimiento de conexiones viales que paulatinamente daban forma al Gran Área Metropolitana. El abordaje histórico del centro provincial no tiene equivalentes en el conjunto de su obra investigativa, si tomamos en cuenta que las publicaciones sobre otras capitales y ciudades fueron más esporádicas y enfocadas en dimensiones específicas. Por ejemplo, los escritos dedicados a las ciudades norteamericanas (Bernal Ponce, 1987).

9 Entre las publicaciones anteriores a 1990 relativas a este periodo histórico están varios libros y artículos de historiadores como Carlos Meléndez y Claudia Quirós. Se acota que la especificidad del tema de la espacialidad josefina de la colonia fue menos desarrollado, por ejemplo, en escritos como González Víquez, Cleto. (octubre 1920). “San José y sus comienzos (1)”. En Revista de Costa Rica, 2, 1-63. 
Por ende, es notable el seguimiento temporal que desarrolló durante su trayectoria profesional, el cual se materializó en el capítulo correspondiente a San José en el libro Ciudades del Caribe y Centroamérica (1993a, pp. 247-281), el que se encuentra acompañado de una cantidad significativa de ilustraciones con las que se recorre el devenir histórico desde la época colonial hasta finales del siglo XIX, constituyéndose en un punto de apoyo importante que complementa la explicación especializada propuesta 15 años antes. En la mimeografía "Una biografía de San José" (Bernal, 1992), el abordaje temporal se prolongó hasta fines de los años ochenta, periodo al que se suma el artículo "Reflexiones sobre el San José de 1990" (Bernal, 1990b).

El último texto mencionado es una compilación inédita de artículos emitidos en fechas anteriores, así como de borradores que posteriormente fueron publicados. Apoyándose principalmente en fuentes secundarias, investigación propia, ilustraciones de su autoría y de otros libros, así como en los resultados de los Seminarios de Graduación en Historia Urbana, la obra es una reseña de larga data. En relación con el contenido, los aportes de mayor peso se encuentran en las ilustraciones propias del autor, pero sobre todo en las críticas a los continuos emprendimientos urbanísticos carentes de planificación realizados desde el siglo $\mathrm{XIX}^{10}$, los cuestionamientos a los patrones de segregación poblacional según clases económicas y en los alegatos contra la construcción masiva, exenta de medidas de protección al patrimonio arquitectónico en el centro de la ciudad y en barrios aledaños. Entre los efectos asociados a este problema, señaló sobre el derribo del Palacio Nacional en 1958:

En términos generales, luego de la destrucción del Palacio Nacional, la reubicación del aparato estatal se hizo sin plan urbanístico, ausente de todo criterio que ordenara su elemento. San José no sólo perdió con ella edificios venerables, sino que desde entonces se vio sometido a la ley del desorden y la yuxtaposición indiscriminada de estilos. (Bernal, 1992, p. 86)

En sus últimos escritos, relativos a la contemporaneidad del paisaje capitalino (Bernal Ponce, 1990b, Bernal Ponce, 1992), se alejó de la perspectiva histórica, para priorizar la exposición de un balance sobre los resultados del proceso de expansión urbana e institucional concomitante al modelo estatal neoliberal. En ellos establece una crítica a la segregación espacial según la clase socioeconómica, a la vez que enumera

10 Siguiendo el patrón argumentativo fundamentado en comparaciones, acotó sobre las construcciones impulsadas por la oligarquía cafetalera: "Los "barones del café" no lograron plasmar en nuestras calles los esquemas del París de Haussmann ni la beautiful city norteamericana, ja lo mejor ni se lo propusieron! Las inserciones de nuevos edificios fueron poco afortunadas en términos de ejes y encuadres paisajísticos, se los distribuyó al azar por aquí y por allá sobre la trama colonial sin perspicacia escenográfica. La clase política, salvo en la ocasión de la construcción del Teatro Nacional, demostró poca sensibilidad hacia los signos arquitectónicos que sostienen la formalidad institucional” (Bernal Ponce, 1992, p. 45). 
las múltiples dificultades organizacionales y de vialidad propias de la configuración urbanística.

En una entrevista al arquitecto sobre los problemas de la capital como tema vigente en los albores de la década de 1990, este puntualizó: "Se habla de San José porque los problemas han llegado a un punto ineludible. Anteriormente se mencionaba a nuestra capital como la ciudad más fea, pero ahora se pasó de un dolor estético a un dolo físico, pasamos de un plano de sobrevivencia en el cual el josefino padece duramente" (Grané, 1990, p. 38). La declaración no pierde su vigencia, pues como bien lo señaló en sus diversos escritos, las ventajas del San José actual así como sus dificultades urbanísticas, son el efecto de siglos de una planificación carente de proyecciones a futuro, en la que el caos estilístico y de diseño se trasladó a la movilidad y al paulatino abandono de la población del casco central.

\section{Conclusiones}

El asiduo trabajo investigativo del arquitecto chileno Juan Bernal Ponce estuvo definido por su perfil de autor-observador, pues mientras estudió el devenir de la constitución morfológica josefina, destacando la confluencia de estilos, las oscilaciones económicas y sociales narradas por la arquitectura, articuló también una crítica bien fundamentada sobre las dificultades en la distribución espacial y la planificación urbanística. Dichos conflictos -señaló- no eran producto de la casualidad, sino de un continuum de malas decisiones en el plano logístico organizativo de las autoridades de la ciudad.

Más allá de los conocimientos que desarrolló sobre las particularidades paisajísticas de San José, este proceso analítico debe ser contemplado a partir de dos elementos fundamentales: uno, que este estudio meticuloso se circunscribió al conjunto de un área temática a la que se abocó. Es decir, no únicamente analizó esta localidad, sino que los artículos antes presentados forman parte de un corpus académico que mantuvo como eje vertebral la indagación de las ciudades, concebidas como espacios vivos, dinámicos y como textos a ser interpretados. Segundo, que la solidez del trabajo relativo a esta región, evidencia formas propias de construir saberes desde el exilio, en tanto el investigador entabló un diálogo con San José valiéndose de sus recursos culturales, para establecer comparaciones con las que identificó y explicó la particular fisonomía de la capital costarricense. Es posible rastrear el ejercicio de diálogo y apropiación de la historia josefina, no solo en el estudio de los textos escritos, sino también de las imágenes de la ciudad, pues son textos por sí mismas, en las que representó edificios icónicos como el Teatro Nacional, los espacios públicos, la arquitectura comercial y vernácula. 
Por otra parte, la faceta escrituraria de Bernal Ponce debe ser interpretada como uno más de los medios de los que él se valió para encontrar un lugar en el ámbito intelectual costarricense, como forma de validarse como sujeto y como artista, ante la pérdida irrevocable de sus puntos de referencia en Chile. La escritura pudo constituirse, entonces, en un ejercicio de validación gremial, en una estrategia de proyección y crecimiento intelectual, y en un medio para redefinirse como sujeto socialmente activo, que produjo aportes en el proceso de reconocimiento espacial experimentado y percibido desde el exilio.

\section{Referencias}

Bernal Ponce, J. y Jankilevich, C. (diciembre 1977). Memoria descriptiva del proyecto Jardín Botánico Henry Pittier. Costa Rica: OFIPLAN, MCJD.

Bernal Ponce, J. (s. f.). Curriculum Vitae.

Bernal Ponce, J. (1967). Arquitectura espontánea de una ciudad anfiteatro, Valparaíso. Boletín de la Universidad de Chile 73.

Bernal Ponce, J. (1977). La arquitectura en hierro y el Centro Pompidou. Habitar, 3, 22-6.

Bernal Ponce, J. (Octubre 1978). San José y la ciudad americana, parte 1. Revista del Colegio Federado de Ingenieros y Arquitectos, 67, 23-8.

Bernal Ponce, J. (Enero 1979). San José y la ciudad americana, parte 2. Revista del Colegio Federado de Ingenieros y Arquitectos, 68, 53-62.

Bernal Ponce, J. (1979). Arquigraba 1979. San José, Costa Rica: Escuela de Arquitectura.

Bernal Ponce, J. (1985). La Habana vieja: Lápiz en mano. Habitar, 18, 12-6.

Bernal Ponce, J. (Julio 1987). Morfología de la ciudad norteamericana. Habitar, 23, 36-40.

Bernal Ponce, J. (1988). Ocho ciudades y un poeta. Revista Herencias 1 (1), 56, 1-52

Bernal Ponce, J. (1989). Panamá, conexión entre dos mundos. Habitar, 26, 34-9.

Bernal Ponce, J. (1989). Lesmes Jiménez y Jaime Carranza: Arquitectos del San José Republicano. Revista Nacional de Cultura, 4, 16-19.

Bernal Ponce, J. (1990a). Reflexiones sobre el San José de 1990. Revista Herencias, 2(2), 49-55.

Bernal Ponce, J. (1990b). Aspectos comparativos entre las ciudades coloniales españolas, inglesas y francesas en el Caribe. Revista del Colegio Federado de Ingenieros y Arquitectos 4, año 33, 22-7. 
Bernal Ponce, J. (16 de octubre 1991). De Valparaíso a París, autobiografía profesional. Mimeografía.

Bernal Ponce, J. (1992). Una biografía de San José. Mimeografía.

Bernal Ponce, J. (1993a). Ciudades del Caribe y Centroamérica del siglo XV al siglo XIX. Costa Rica: Editorial del Instituto Tecnológico de Costa Rica.

Bernal Ponce, J. (1993b). Arquitectura victoriana en el Caribe y Costa Rica. Revista Herencia, 2(5), 23-31.

Bernal Ponce, J. (2000). Un chileno en Costa Rica. Folleto de la exposición el Museo de Arte Costarricense. Costa Rica: MCJD.

Bernal Ponce, J. (2000). Valparaíso, Patrimonio de la Humanidad. Habitar, 43, 32-6.

Dobles, A. (10 de setiembre 1994). Crítica de arte con nueva pluma. La Nación, 15 B.

Grané, J. (1990). Entrevista a los arquitectos Agustín Mourelo y Juan Bernal Ponce. Habitar, $60,38-9$.

Hernández, E. y Arguedas, A. (2018). Tinta y papel: El grabado en Costa Rica 1934-2000. Costa Rica: EUNA.

Museo Nacional de Bellas Artes. (s. f.). Juan Bernal Ponce-Artistas Visuales. http://www.artistasvisualeschilenos.cl/658/w3-article-40332.html

Nitshchack, H. (2010). El sujeto del exilio. En Carlos Sanhueza, La patria interrumpida: Latinoamericanos en el exilio. LOM Ediciones.

Oliva Medina, M. (2018). Julio Escámez Carrasco: Un largo exilio de un pintor americano y universal. En Exiliados, expatriados e integrados: Chilenos en Costa Rica. En prensa.

Rama, Á. (1998). La ciudad letrada. Bolivia: Arca.

Ramírez Hernández, M. (2018). Base de datos de producción escrita de chilenos en el exilio en Costa Rica. Proyecto Voces y rostros del exilio chileno. Instituto de Estudios Latinoamericanos, UNA.

Said, E. (1996). Representaciones del intelectual. España: Ediciones Paidós Ibérica. 
